ends-and when they touch, weld together, and their surfaces become metallic, like graphite.

Diamonds heated in charcoal tubes were suddenly changed and became conductors. Still more remarkable effects were produced when he used collaterally with the 600 Bunsens 135 Muncké with zincs $13 \frac{3}{4} \mathrm{in}$. high and $19 \frac{2}{3}$ in. wide. With these sugar-charcoal was volatilised immediately.

I think it may be inferred from these facts that even at the temperature of a powerful electric arc enough charcoal vapour may be present to form its spectrum, and there is little doubt that the temperature of discharge of a good inductorium combined with a sufficient condenser is still hotter than the arc.

It is to be noticed that Despretz in these experiments anticipated Dr. Siemens's electric furnace. He mentions that he fused $375^{\circ}$ grains of platinum in a few minutes, and could have done more had he had a larger crucible.

\section{A Case of Fascination}

Some years ago it was my fortune to witness a case of "fascination" between a large striped snake and a medium-sized toad. When first seen they were about fifteen inches apart. The snake lay in a coil with its head thrust out towards its victim, and moving slowly, its eyes glittering and its tongue darting incessantly.

The toad was standing on the very tips of its claws, with its limbs rigidly drawn up to their full length, its eyes fixed upon its captor and fairly bursting from their sockets, its mouth covered with foam, and its whole body swaying to and fro, and seeming just ready to pitch forward upon its face.

The movement of the snake became more and more rapid, and the agitation of the toad more intense, until the space between them was reduced to some three or four inches, when the snake opened wide its mouth, and the laboured breathing of its victim stopped short in a low guttural moan.

At this point my own agitation became so great that, seizing a heavy stone, I finished the snake at one blow. The instant the snake was struck the toad fell backward as suddenly as though itself had been hit, and lay upon its back for some minutes with no signs of life. At length it gained its feet and began to creep languidly away.

Lyons, N.Y., January is

J. T. BROWNELL

\section{Birds Laying in January}

As a proof of the unusual mildness of the weather just previous to the intense frost and severe snowstorms most parts of the country have lately been suffering from, it may interest some of your readers to learn that not far from this place, on the $13^{\text {th }}$ Jan., a wren's nest with seven eggs in it, quite fresh, was taken. The nest I have in my possession, and it bears every evidence of having been lately tenanted. The eggs, I am sorry to say, are broken; they were placed in a cup for safety, and were most unfortunately knocked down when the room was dusted, giving however unmistakable prosf of their having been but lately laid.

I do not know whether there is any instance on record of a wren's nest having been found in January before.

\section{JOHN H. WILLMORE}

Queenwood College, near Stockbridge, Hants, January 28

\section{Vibration of Telegraph Wires during Frost}

While walking with my son by the Liverpool, Crosby, and Southport Railway between Crosby and Hall Roait stations he called my attention to the telegraph wires, which were in a state of rapid vibration. The day was frosty, the time Ir.3o a.m., and the sun, which had been showing us a bright disk through the haze was beginning to throw out rays and shine a little strongly. At first I thought the movement must be only apparent -a mere optical delusion-as the air was perfectly calm. A closer examination convinced me to the contrary, as the under part of the wires were covered with pendant ice needles, a sort of rime, which moved to and fro indicating a torsional or twisting vibration of the wires, and as the rapidity of the vibrations decreased this was more clearly seen. In about five minutes the movement ceased, and $I$ have not noticed it since, though I have frequently passed under the wires on my way to skate. Can any of your correspondents account for the phenomenon? It appeared as if in some way connected with previous contraction by the frost and sudden expansion in jerk; by the sun's rays. My son informs me that two years ago, during a frost, he noticed the strained wires of a garden-fence behaving in the same curious way.

Park Corner, Blundellsands

T. Mellard Reade

\section{"Mock Sun"}

I SEND a sketch of a parhelion which I saw from the East Cliff, Hastings, on Thursday, January 20, at 3 p.m. The crescents above the sun were fairly bright and well developed, and there were faint traces of a second ring outside, and some distance from, the first.

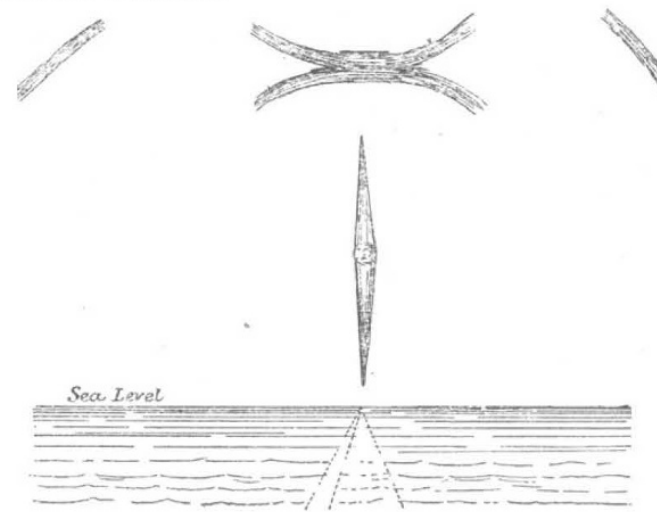

There was a slight fog at the time, with a north-east wind and hard frost, which has continued up to this time. We have had no snow here since that "terrible Tuesday," the 18 th.

I do not remember ever having seen this phenomenon before, except in pictures of the Arctic Regions.

St. Leonards, January 24

J. E. H. Peyton

\section{ON SOME RECENT CHARTS AND MAPS OF CURVES OF EQUAL MAGNETIC VARIATION OR DECLINATION}

SINCE the year I7or, when Halley published his famous chart showing curves of equal magnetic variation for the Atlantic and Indian Oceans, the construction of similar charts, amended and enlarged as data increased, has been of great interest to magnetic science and of practical value to the navigator.

Halley's chart of I7or was expanded to embrace the navigable parts of the whole world, and brought up to the epoch 1756 by Mountaine and Dodson, whose labours were followed by those of Churchman in 1794, Yeates in I8I7, and Hansteen (for several distinct epochs between 1600 and 1787 ) in 1819 . In 1833 Barlow's chart, together with curves for the North Polar regions, accompanied a descriptive paper in the Phil. Trans. for that year.

In I840 Gauss and Weber's charts of theoretical curves of the three magnetic elements for the whole world, including special Polar charts, were published. These curves were culculated on the basis of a mathematical theory founded upon a large number of observations fairly distributed over the surface of the globe.

About this latter period the practice of ascertaining the errors of the compass on shipboard (as due to the effects of iron) for every ship in the Royal Navy, at certain periods and on change of magnetic latitude, was established by the Admiralty on the recommendation of a compass committee specially appointed to consider the question of compass efficiency and management. This, as bearing on the subject under review, was an important step towards obtaining reliable data for the construction of Variation charts now becoming so essential an element in navigation.

Following on this, Archibald Smith's mathematical investigations of the theory of the deviations of the compass on board ship enabled Sabine to correct observations made in the Atlantic and the Antarctic Oceans 